\title{
Conservation challenges and action for the Critically Endangered Singapore freshwater crab Johora singaporensis
}

\author{
Daniel J.J. Ng, Darren C.J. Yeo, N. Sivasothi and Peter K.L. Ng
}

\begin{abstract}
The Singapore freshwater crab Johora singaporensis is known only from three streams in Singapore and is among the top 100 most threatened species in the world. It is the only member of the genus Johora, endemic to the Malay Peninsula, to be categorized as Critically Endangered on the IUCN Red List. Extensive surveys conducted over 1 year to determine the extent of the species' distribution revealed that the population has declined significantly at its type locality in Bukit Timah Nature Reserve, Singapore Island's oldest protected forest area. The species remains extant in two unprotected streams in Bukit Batok and Bukit Gombak, which are located outside the nature reserve. Acidification of streams as a result of acid precipitation may be a factor in the decline of the species. If so, this will be the first documented instance of a species being affected negatively by anthropogenic acidification of a tropical freshwater system. The occurrence of this threatened species in a protected area has not, therefore, guaranteed its survival. There is a need for long-term and continuous monitoring of species of high conservation value, together with other measures that focus on habitat protection. Conservation efforts by the National Parks Board of Singapore in collaboration with other government agencies are ongoing in an effort to ensure the survival of this important species.
\end{abstract}

Keywords Acid precipitation, Bukit Timah Nature Reserve, freshwater decapod crustacean, Potamidae, Singapore, stream acidification

\section{Introduction}

$\mathrm{D}$ ecapod crustaceans perform an important role in ecosystem function in tropical streams, serving as detritivores and omnivorous consumers (Mantel \& Dudgeon, 2004; De Souza \& Moulton, 2005) and as an important food source for predators (Hinojosa-Garro \& Zambrano, 2004; Nyström et al., 2006). However, relatively

Daniel J.J. Ng (Corresponding author), Darren C.J. Yeo and N. Sivasothi Department of Biological Sciences, National University of Singapore, 14 Science Drive 4, Singapore 117543, Republic of Singapore

E-mail pentagon762000@hotmail.com

Peter K.L. NG Department of Biological Sciences, Raffles Museum of Biodiversity Research, National University of Singapore, Republic of Singapore

Received 30 November 2012. Revision requested 8 January 2013.

Accepted 5 April 2013. First published online 29 April 2014. little is known about the ecology of tropical stream decapods, with most studies focused on their zoogeography and taxonomy (Dobson et al., 2007).

Primary freshwater crabs of the superfamily Potamoidea are arguably the least well studied freshwater decapods. These crabs are adapted to freshwater environments and are independent of the marine environment for their entire life cycle (Yeo et al., 2008a). Many primary freshwater crabs have a restricted geographical distribution, show a high degree of endemism, and display direct development, producing small broods of large, yolky eggs, which hatch directly into juvenile crabs (Hartnoll, 1988; Ng, 1988; Anger, 1995; Yeo et al., 2008a; Cumberlidge et al., 2009).

Anthropogenic habitat disturbance is threatening many species of freshwater crabs, with potamids and pseudothelphusids facing the highest risk of extinction (Cumberlidge et al., 2009). Species under threat are often semi-terrestrial, with restricted distributions (Cumberlidge et al., 2009). Stenotopic species that are endemic to islands are vulnerable to human-induced disturbances such as development and pollution (Bahir et al., 2005; Ng \& Yeo, 2007; Yeo et al., 2008a; Cumberlidge et al., 2009). Conserving these species is challenging, as they are often found in unprotected areas (Cumberlidge et al., 2009) and therefore their decline may go unnoticed because of lack of monitoring ( $\mathrm{Ng} \&$ Yeo, 2007).

The freshwater crab fauna of Singapore consists of six species in three families: Geosesarma peraccae and Geosesarma nemesis (Sesarmidae), Parathelphusa maculata, Parathelphusa reticulata and Irmengardia johnsoni (Gecarcinucidae), and Johora singaporensis (Potamidae). The latter three are endemic $(\mathrm{Ng}, 1990,1997)$. With the exception of $P$. maculata, the species are mostly confined to forest streams $(\mathrm{Ng}, 1997)$.

The endemic Singapore freshwater crab J. singaporensis $\mathrm{Ng}, 1986$ is one of only three freshwater invertebrates in the top 100 most threatened species (Baillie \& Butcher, 2012). Although most species of Johora are confined to relatively fast-flowing streams in montane regions (Yeo et al., 2007), J. singaporensis is found at relatively low altitudes, although restricted to hilly parts $(\mathrm{Ng}, 1988)$. First discovered at Jungle Fall Valley stream in Bukit Timah Nature Reserve in 1986, the species was only known from this type locality until subsequent surveys of other parts of the island revealed two other populations in the early 1990s. Historically, the type locality supported the largest population, although numbers 


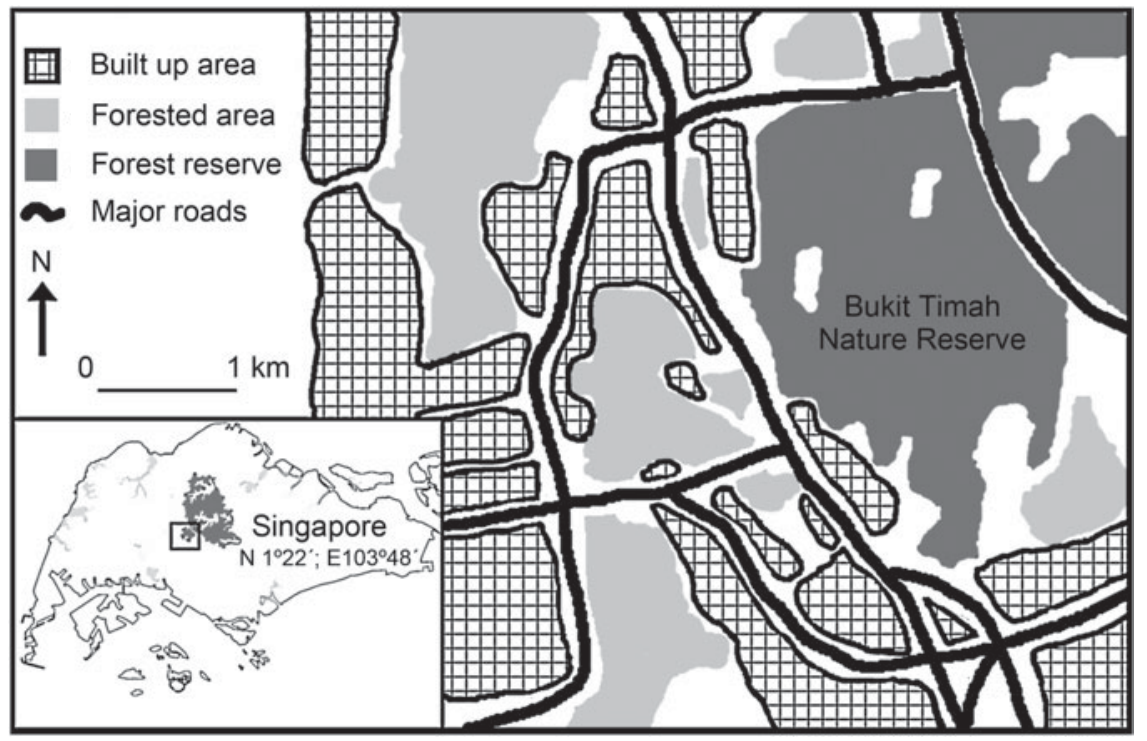

Fig. 1 The study area, with built-up areas and major roads (exact localities of the Singapore freshwater crab Johora singaporensis populations have been omitted at the request of the National Parks Board). The rectangle on the inset indicates the location of the main map in Singapore. there appeared to have fallen (Ng, 1995, 1997), with the last confirmed sighting in the early 1990s. Prior to this study J. singaporensis had only been reported from the two other locations: a stream within a small patch of disturbed secondary forest close to Bukit Batok Nature Park, and a stream at Ministry of Defence land at Bukit Gombak (Ng, 1990, 1995, 1997; Yeo et al., 2008b). Bukit Timah Nature Reserve is one of only four gazetted nature reserves with the highest level of protection in Singapore; the other two known locations of the species are not within a formal nature reserve and are therefore unprotected. The ecological information available for this species is based on ad-hoc observations and no systematic ecological study has been carried out (Ng, 1988; Ng \& Yeo, 2013). The species was initially categorized as Endangered on the IUCN Red List (Yeo et al., 2008b), based on its restricted range, but following a reappraisal it was categorized as Critically Endangered (Cumberlidge et al., 2009). J. singaporensis is part of a basal lineage of Johora (Yeo et al., 2007) and represents the southern limit for the distribution of the genus (Ng, 1988), which makes its conservation an even greater priority. Our objectives were to determine the status of J. singaporensis through a survey of its known distribution range, including historical collection sites, and to assess the challenges for its conservation.

\section{Study area}

Singapore $\left(\mathrm{c} .700 \mathrm{~km}^{2}\right)$ is an island in South-east Asia, at the southern tip of the Malay Peninsula. It is a highly urbanized lowland island, with only remnants of primary forest remaining (Corlett, 1997). The temperature is relatively consistent, with an annual mean of $27^{\circ} \mathrm{C}$, mean annual relative humidity is $84.2 \%$, and rain falls throughout the year (2,342 $\mathrm{mm}$ annual total).
Singapore has few hill streams. These are usually shallow $\left(<_{1} \mathrm{~m}\right)$, fast flowing, well shaded by the forest canopy but sparse in riparian vegetation, and less disturbed than lowland streams. The substratum consists mainly of rocks and/or sand, with accumulations of leaf litter (Ng, 1991, 1994; Yeo \& Lim, 2011).

Based on Ng (1990, 1995, 1997), museum records in the Raffles Museum of Biodiversity Research at the National University of Singapore, our own unpublished data (PKLN and DCJY), and discussions with carcinologists who have worked and sampled in freshwater environments in Singapore (C.D. Schubart, S.H. Tan \& N. Tohru), the known distribution of J. singaporensis comprised three sites: a stream at Jungle Fall Valley in Bukit Timah Nature Reserve $\left(\mathrm{S}_{1}\right)$, a stream in Bukit Gombak $\left(\mathrm{S}_{2}\right)$ and a stream in Bukit Batok $\left(S_{3}\right)$. The exact locations of these sites are not shown (Fig. 1), to prevent poaching.

\section{Methods}

We surveyed all three sites during October 2007-February 2008 to determine the status of their J. singaporensis populations. Care was taken to minimize disturbance to the species.

We conducted preliminary surveys ( 1 day and 1 night), including sieving coarse woody debris and leaf litter, to determine whether the species was present at each of the three sites. We detected J. singaporensis at $\mathrm{S}_{2}$ and $\mathrm{S}_{3}$ but not at S1.

Based on the preliminary surveys we set different objectives for each site. At $S_{1}$ the objective was to conduct a thorough investigation to determine if J. singaporensis was present. On eight occasions two experienced field workers searched the entire stream by hand during 19.30-21.30. They wore headlamps and combed through coarse debris, turning 
TABLE 1 Results of the surveys for the Singapore freshwater crab Johora Singaporensis, from three sites in Singapore (Fig. 1), with mean number of individuals detected per survey, density, and water $\mathrm{pH}$. One-way ANOVA was used to compare numbers detected per survey, density and $\mathrm{pH}$ between sites. The Student-Newman-Keuls test was used to assess the difference in $\mathrm{pH}$ between sites.

\begin{tabular}{llll}
\hline Site & $\begin{array}{l}\text { Mean no. of } \\
\text { individuals } \pm \mathrm{SE}^{1}\end{array}$ & $\begin{array}{l}\text { Mean density } \pm \mathrm{SE} \\
\left(\mathrm{m}^{-2}\right)^{1}\end{array}$ & $\mathrm{pH} \pm \mathrm{SE}^{2}$ \\
\hline Bukit Timah Nature Reserve (S1) & 0 & 0 & $4.5 \pm 0.2$ \\
Bukit Gombak (S2) & $9 \pm 1$ & $3 \pm 0.5$ & $6.6 \pm 0.2$ \\
Bukit Batok (S3) & $27 \pm 2$ & $10 \pm 0.8$ & $6.4 \pm 0.2$ \\
\hline
\end{tabular}

${ }^{1}$ Significant difference between $S_{2}$ and $S_{3}$

${ }^{2}$ Significant difference between $S_{1}$ and $S_{2}$ and between $S_{1}$ and $S_{3}$

over small rocks. Nocturnal surveys were conducted because the results of the preliminary surveys suggested that the species was more active and more easily observed at night. In addition, two 3-hour surveys were conducted in the daytime, during 09.30-12.30, using a hand-held push net $\left(0.25 \mathrm{~m}^{2}\right.$, mesh size $\left.0.5 \mathrm{~mm}\right)$. To minimize disturbance to the habitat, care was taken to restore sifted or overturned leaf litter and stones to their original location at the end of each session.

For $S_{2}$ and $S_{3}$ our objective was to determine the population densities of J. singaporensis at these sites. Ten $50 \times 50 \mathrm{~cm}$ quadrats were chosen randomly and searched at night (after 19.30) by two experienced field workers, using headlamps. Each site was sampled on eight occasions. The maximum carapace length of captured crabs (widest part across the carapace) was measured in the field, to the nearest $0.01 \mathrm{~mm}$, using a dial calliper. Gender of adults was determined on the basis of abdomen morphology, with adult males characterized by a triangular-shaped abdomen and adult females by a broad oval-shaped abdomen. The abdomens of smaller individuals (maximum carapace length $<_{13} \mathrm{~mm}$ ) are morphologically indistinct and thus could not be differentiated in the field. As such, smaller individuals were considered to be juveniles. Similar care was taken to minimize disturbance to the habitat at sites $S_{2}$ and $\mathrm{S}_{3}$. Water $\mathrm{pH}$ was measured at the start of each survey.

One-way ANOVA was used for inter-site comparison of the number of $J$. singaporensis observed per survey, population density and water $\mathrm{pH}$. The Student-NewmanKeuls post-hoc test was used to detect significant differences in the $\mathrm{pH}$ between sites. Significance levels for all tests were set at $\mathrm{P}<0.05$. Population density $\left(\right.$ per $\left.\mathrm{m}^{2}\right)$ was calculated as the number of crabs per quadrat divided by the quadrat area. To calculate the probability of species absence the formula $(1-P)^{n}$ was used, where $n$ is the number of surveys and $\mathrm{P}$ is the mean probability of detection for these three historical sites (McArdle, 1990).

\section{Results}

J. singaporensis was absent from $\mathrm{S}_{1}$ (confidence level $>99.9 \%$ ) but present at $S_{2}$ and $S_{3}$ (Table 1). The number
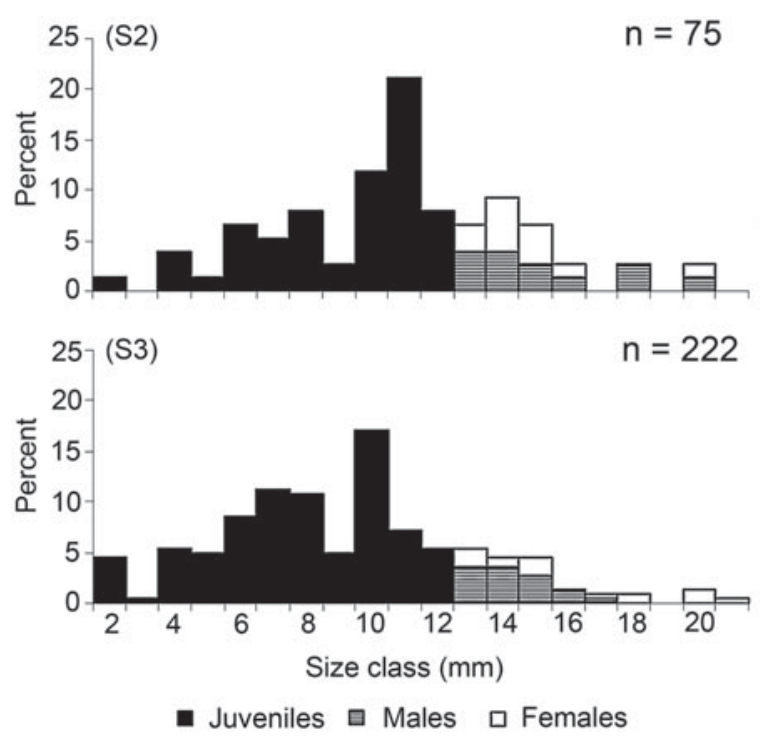

FIG. 2 Size-frequency distributions of J. singaporensis at $\mathrm{S}_{2}$ and $\mathrm{S}_{3}$.

of crabs observed per survey and the population density of J. singaporensis were significantly greater at $S_{3}$ compared to $\mathrm{S}_{2}$ (Table 1). The water $\mathrm{pH}$ at $\mathrm{S}_{1}$ was significantly lower than at the other two sites (Table 1). A follow-up survey also discovered a small population of J. singaporensis in a stream in another part of Bukit Timah Nature Reserve, where the $\mathrm{pH}$ was higher compared to $\mathrm{S}_{1}(\mathrm{Ng}, 2008)$.

Over the sampling period of 4 months, 75 individuals of J. singaporensis, comprising 11 males, 12 females and 52 juveniles, were observed at $S_{2}$. An equal sampling effort at $S_{3}$ yielded a total of 222 individuals: 26 males, 17 females and 179 juveniles (Fig. 2). No ovigerous or brooding crabs were observed.

\section{Discussion}

\section{Population status}

The results indicate a significantly higher population density of J. singaporensis at $\mathrm{S}_{3}$ compared to $\mathrm{S}_{2}$ (Table 1 ). A possible reason for this is the presence at $S_{2}$ of a second 
species of freshwater crab, the gecarcinucid P. maculata, which is absent from $S_{3}$. Adults of this more aggressive sympatric species are larger (maximum carapace length $>50 \mathrm{~mm}$ in P. maculata, c. $20 \mathrm{~mm}$ in J. singaporensis) and may be competing for limited resources such as food and shelter as well as being a predator of $J$. singaporensis (Ng, 1989; authors, pers. obs.). Another consideration is that the stream at $S_{2}$ runs through an ornamental plant garden, whereas the stream at $\mathrm{S}_{3}$ flows through secondary forest. Other factors such as the quality of the habitat, the number of predators and the amount of food available could potentially influence the population (Donnay \& Beissinger, 1993).

A total of 10 surveys (two diurnal and eight nocturnal) failed to detect $J$. singaporensis in the type locality in Bukit Timah Nature Reserve $\left(S_{1}\right)$, indicating at the very least a significant population decline, with the possibility that the species may have been extirpated where it was originally discovered. This stream is located in a natural area with the highest level of formal protection in Singapore, and the population of $J$. singaporensis there was assumed to be secure and generally free from anthropogenic disturbances. Perhaps for this reason, as well as to minimize disturbance to the species and the locality, this site was rarely surveyed. After the two other populations were discovered, a few subsequent scientific collections of specimens were all conducted at these unprotected sites, mainly for systematic work.

\section{Population structure}

Estimating freshwater crab populations is challenging, with different sampling methods predisposed to detecting different size classes (Kino, 1990; Dobson et al., 2007). Dobson et al. (2007) reported that baited traps selectively captured larger crabs, whereas Surber samplers tended to collect smaller crabs; they also reported that only a small number of crabs belonging to the largest size class were captured during an active search by hand, which is consistent with the results of our intensive physical searches.

The absence of brooding or ovigerous females suggests possible cryptic behaviour. Females may have been hiding in water-filled excavations located further away from the stream, to protect their broods from predators. This behaviour has been suggested for the freshwater crabs Geosesarma notophorum (Ng \& Tan, 1995) and Trichodactylus fluviatilis (Alarcón et al., 2002). There is also the possible influence of seasonality (we did not survey throughout the year). This possibility is being investigated in an ongoing collaborative project between the National Parks Board of Singapore and the National University of Singapore, which will involve sampling over 1 year.

\section{Stream acidification—a possible cause of decline?}

Acidification is one possible reason for the apparent disappearance of J. singaporensis at stream S1. It appears that this acidification has occurred relatively recently, in the 1990s; the $\mathrm{pH}$ at $\mathrm{S}_{1}$ was 5-6 in the early 1990 (Ong, 1965; P.K.L. Ng, unpubl. data). The persistence of J. singaporensis in the other streams, where the $\mathrm{pH}$ is significantly higher (Table 1), seems to corroborate its absence in S1. The decrease in $\mathrm{pH}$ at $\mathrm{S} 1$ may be attributable to acid precipitation (mean $\mathrm{pH}$ of precipitation in Singapore is 4.1-4.5; Balasubramanian et al., 2001; Zhong et al., 2001; Hu et al., 2003), with the difference in $\mathrm{pH}$ between $\mathrm{S}_{1}$ and streams $\mathrm{S}_{2}$ and $S_{3}$ possibly maintained by different buffering capabilities of the bedrock of the streams (Hornung et al., 1995). However, this is difficult to verify because of the lack of long-term data on the $\mathrm{pH}$ of precipitation and of the streams. We cannot rule out the possibility of other causes of stream acidification, such as subterranean exposure of sulphur or sulphide deposits or decomposition of vegetation (Kwok, 2010).

Stream acidification can lead to a reduction in the diversity of freshwater organisms (Feldman \& Connor, 1992; Courtney \& Clements, 1998). In particular, it is known to have caused declines, or even extirpation, of freshwater crayfish (Malley, 1980; Berrill et al., 1985; France \& Collins, 1993). Species may be intolerant of the altered chemical composition of acidified water (Sutcliffe \& Hildrew, 1989; Rosemond et al., 1992) or they may be affected indirectly through microhabitat modification and food reduction. However, there are no equivalent studies for any species of freshwater crab. It is possible that in the case of J. singaporensis, juveniles, eggs and individuals that are undergoing ecdysis may be more vulnerable to acidic waters than adults (Y.K. Ip, pers. comm.).

J. singaporensis is the first tropical freshwater invertebrate for which a significant decline has been documented. There are two other endemic crab species in Singapore, I. johnsoni and $P$. reticulata, which are found only in certain lowland forest streams and freshwater swamp habitats in nature reserves. However, they are believed to be less at risk from acidification because the $\mathrm{pH}$ of their preferred habitats is naturally lower ( $\mathrm{pH} 5 ; \mathrm{Ng} \& \mathrm{Lim}, 1992)$. I. johnsoni is still relatively common at $\mathrm{S} 1$, where $J$. singaporensis has disappeared. However, it is not known whether the drop in $\mathrm{pH}$ affected population levels of I. johnsoni, because there is a lack of baseline data for this species.

Acid precipitation can have far-reaching consequences for all taxa in an ecosystem. It is a growing problem especially in developing countries with rapidly rising emissions of sulphur and nitrogen oxides but, despite its ecological effects, it remains relatively poorly studied in the tropics (Galloway, 1995). Based on soil type, land cover and soil moisture, regions that are particularly sensitive to acidic 
deposition include southern China, parts of South-east Asia, Amazonia, and Central Africa (Kuylenstierna et al., 1995, 2001). As these areas are rich in biodiversity and high in endemism (Myers et al., 2000), it is projected that many aquatic species with stenotopic habitat preferences will be threatened by acid rain in the future.

\section{Conservation challenges and action}

Anthropogenic disturbance continues to threaten the survival of $J$. singaporensis at the two unprotected sites where the species is extant. At S2 a heavy rainfall event in December 2006 caused a landslide along a portion of the hill catchment upstream, and drainage modification measures were taken in early 2008 to address this problem. These measures diverted subterranean water away from the stream and caused a drop in the water table and a reduction in water flow (authors, pers. obs.). The relevant authorities were informed promptly and re-diversion of the water source restored the water flow (authors, pers. obs.) but siltation has increased. The land at $S_{3}$ has been designated for residential use and such development could threaten the survival of the largest known population of J. singaporensis (Ng et al., 2011).

Conserving the natural environment while maintaining economic growth and development poses a challenge in Singapore, where land is scarce. The remaining forested areas are fragmented and under pressure to be converted for other use (Fig. 1). A balance between development and habitat conservation is required, with conservation priority preferably being given to areas with endemic species such as J. singaporensis. Efforts are being made to improve connectivity between the fragmented forested/vegetated patches in Singapore, with the construction of Eco-Link, a bridge planted with vegetation, spanning a six-lane highway, to connect the Bukit Timah Nature Reserve and the larger Central Catchment Nature Reserve (NParks, 2011), and the Park Connector Network, which links green areas (e.g. urban parks) and forested nature reserves throughout Singapore.

Following the completion of this study in 2008 the National Parks Board of Singapore was informed about the possible extirpation of $J$. singaporensis from its type locality in Bukit Timah Nature Reserve and embarked on an action plan to conserve the species. Immediate action was taken to survey other hill streams in Bukit Timah, Bukit Batok and Bukit Gombak to determine whether the species could be present at additional sites. This led to the discovery of a population of $J$. singaporensis in a second locality in Bukit Timah, in part of a different drainage system $(\mathrm{Ng}, 2008)$. However, it appears that the population density at this new locality is still lower than that of the other remaining populations at $\mathrm{S}_{2}$ and $\mathrm{S}_{3}(\mathrm{Ng}, 2008)$. This could, in part, be a result of opportunistic predation by the fish Betta pugnax and competition pressure from the prawn Macrobrachium malayanum, which are absent from $\mathrm{S}_{2}$ and $\mathrm{S}_{3}(\mathrm{Ng}, 2008)$. Another possible reason for the low abundance of crabs here could be the relatively low $\mathrm{pH}$ (lower than $\mathrm{S}_{2}$ and $\mathrm{S}_{3}$ but not as low as $\mathrm{S}_{1}$ ). Hydrological and biodiversity studies on hill streams were subsequently conducted to examine the distribution and abundance of $J$. singaporensis and to monitor the conditions of these streams.

The sites of the two unprotected populations are now monitored by the National Parks Board, with the assistance and support of other government agencies, which have taken steps to prevent these two biologically diverse and important sites from being further developed or disturbed.

The status of $J$. singaporensis remains unchanged; its survival is threatened, as it occurs only at three sites and is absent from its type locality. The biology and ecology of the species remain poorly known. However, ongoing research is evaluating in situ and ex situ conservation strategies for the species and studying its biology and ecology. This project will also investigate the optimal physico-chemical and biological conditions for the species, evaluate the current conditions of the sites and recommend remedial actions to optimize them for the species, recommend a method for long-term monitoring, and identify potentially suitable sites in Singapore for population enhancement.

\section{Acknowledgements}

We are grateful to the late Dr Ivan Polunin and his family for generously allowing us to sample the stream on their property, without which this study would not have been possible. We thank Christoph Schubart, David Laurence Higgitt, Alex Ip Yuen Kwong, Tan Swee Hee and Tohru Naruse for their advice, the National Parks Board for granting the survey permit and for providing information included here in the section on conservation action, and Neil Cumberlidge and an anonymous reviewer for their helpful comments and suggestions. We thank the NParks staff Koa Tian Leng and Mishak, who provided field assistance during the follow-up survey. This research was conducted under the permit $\mathrm{NP} / \mathrm{RP}_{743}$ and was partially supported by a grant from the National Parks Board (WBS: R167-000-001-490).

\section{References}

Alarcón, D.A., Arruda Leme, M.H. \& Cobo, V.J. (2002) Population structure of the freshwater crab Trichodactylus fluviatilis. In Modern Approaches to the Study of Crustacea (eds E. Escobar-Briones \& F. Alvarez), pp. 179-182. Kluwer Academic/Plenum Publishers, New York, USA.

Anger, K. (1995) The conquest of freshwater and land by marine crabs: adaptations in life-history patterns and larval bioenergetics. Journal of Experimental Marine Biology and Ecology, 193, 119-145. 
Bahir, M.M., NG, P.K.L., Crandall, K. \& Pethiyagoda, R. (2005) A conservation assessment of the freshwater crabs of Sri Lanka. The Raffles Bulletin of Zoology, 12, 121-126.

B Aillie, J.E.M. \& Butcher, E.R. (2012) Priceless or Worthless? The World's Most Threatened Species. Zoological Society of London, London, UK.

Balasubramanian, R., Victor, T. \& Chun, N. (2001) Chemical and statistical analysis of precipitation in Singapore. Water, Air, and Soil Pollution, 130, 451-456.

Berrill, M., Hollett, L., Margosian, A. \& Hudson, J. (1985) Variation in tolerance to low environmental $\mathrm{pH}$ by the crayfish Orconectes rusticus, O. propinquus, and Cambarus rubustus. Canadian Journal of Zoology, 63, 2586-2589.

Corlett, R.T. (1997) The vegetation in the nature reserves of Singapore. Gardens' Bulletin, Singapore, 49, 147-159.

Courtney, L.A. \& Clements, W.H. (1998) Effects of acidic pH on benthic macroinvertebrate communities in stream microcosms. Hydrobiologia, 379, 135-145.

Cumberlidge, N., NG, P.K.L., Yeo, D.C.J., Magalhaes, C., Campos, M.R., Alvarez, F. et al. (2009) Freshwater crabs and the biodiversity crisis: importance, threats, status, and conservation challenges. Biological Conservation, 142, $1665-1673$.

De Souza, M.L. \& Moulton, T.P. (2005) The effects of shrimps on benthic material in a Brazilian island stream. Freshwater Biology, 50, 592-602.

Dobson, M., Magana, A.M., Lancaster, J. \& Mathooko, J.M. (2007) Aseasonality in the abundance and life history of an ecologically dominant freshwater crab in the Rift Valley, Kenya. Freshwater Biology, 52, 215-225.

Donnay, T.J. \& Beissinger, S.R. (1993) Apple snail Pomacea doliodes and freshwater crab Dilocarcinus dentatus population fluctuations in the Llanos of Venezuela. Biotropica, 25, 206-214.

Feldman, R.S. \& Connor, E.F. (1992) The relationship between pH and community structure of invertebrates in streams of the Shenadoah National Park, Virginia, USA. Freshwater Biology, 27, 261-276.

France, R.L. \& Collins, N.C. (1993) Expatriation of crayfish in a lake affected by long-range anthropogenic acidification. Conservation Biology, 7, 184-188.

Galloway, J.N. (1995) Acid deposition: perspectives in time and space. Water, Air, and Soil Pollution, 85, 15-24.

HartNolL, R.G. (1988) Evolution, systematics and geographical distribution. In Biology of the Land Crabs (eds W.W. Burggren \& B.R. McMahon), pp. 6-53. Cambridge University Press, Cambridge, UK.

Hinojosa-Garro, D. \& Zambrano, L. (2004) Interactions of common carp (Cyprinus carpio) with benthic crayfish decapods in shallow ponds. Hydrobiologia, 515, 115-122.

Hornung, M., Bull, K., Cresser, M.S., Ullyett, J., Hall, J., LANGAN, S.J. et al. (1995) The sensitivity of surface waters of Great Britain to acidification predicted from catchment characteristics. Environmental Pollution, 87, 207-214.

Hu, G.P., Balasubramanian, R. \& Wu, C.D. (2003) Chemical characterization of rainwater at Singapore. Chemosphere, 51, $747-755$.

Kino, H. (1990) Comparison of sampling methods for estimating population structure of the freshwater crab, Geothelphusa dehaani, and infection levels with lung flukes. Japanese Journal of Parasitology, 39, 603-611.

Kuylenstierna, J.C.I., Cambridge, H., Cinderby, S. \& Chadwick, M.J. (1995) Terrestrial ecosystem sensitivity to acid deposition in developing countries. Water, Air, and Soil Pollution, $85,2319-2324$.
Kuylenstierna, J.C.I., Rodhe, H., Cinderby, S. \& Hicks, K. (2001) Acidification in developing countries: ecosystem sensitivity and the critical load approach on a global scale. Ambio, 30, 20-28.

Kwok, C.K. (2010) Is Acidity a Problem in Streams of Bukit Timah Nature Reserve (BTNR)? Http://waterqualityinsingapore.blogspot. $\mathrm{sg} /$ 2010/o2/is-acidity-problem-in-streams-of-bukit.html [accessed 10 April 2012].

Malley, D.F. (1980) Decreased survival and calcium uptake by the crayfish Oronectes virilis in low $\mathrm{pH}$. Canadian Journal of Fisheries and Aquatic Sciences, 37, 364-372.

Mantel, S.K. \& Dudgeon, D. (2004) Growth and production of a tropical predatory shrimp, Macrobrachium hainanense Palaemonidae, in two Hong Kong streams. Freshwater Biology, 49, 1320-1336.

McArdue, B.H. (1990) When are rare species not there? Oikos, 57 , 276-277.

Myers, N., Mittermeier, R.A., Mittermeier, C.G., DA FonseCA, G.A.B. \& Kent, J. (2000) Biodiversity hotspots for conservation priorities. Nature, 403, 853-858.

NG, D.J.J. (2008) Final Report on Stream Survey for Freshwater Crabs. Unpublished report. Singapore National Parks Board, Singapore.

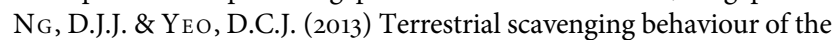
Singapore freshwater crab, Johora singaporensis (Crustacea: Brachyura: Potamidae). Nature in Singapore, 6, 207-210.

NG, P.K.L. (1986) Preliminary descriptions of 17 new freshwater crabs of the genera Geosesarma, Parathelphusa, Johora and Stoliczia (Crustacea Decapoda, Brachyura) from South East Asia. Journal of Singapore National Academy of Science, 15, 36-44.

NG, P.K.L. (1988) The Freshwater Crabs of Peninsular Malaysia and Singapore. Department of Zoology, University of Singapore, Singapore.

NG, P.K.L. (1989) Parathelphusa maculata, the common lowland freshwater crab of Peninsular Malaysia and Singapore. Nature Malaysiana, 14, 130-135.

NG, P.K.L. (1990) The freshwater crabs and prawns of Singapore. In Essays in Zoology (eds L.M. Chou \& P.K.L. Ng), pp. 189-204. Department of Zoology, National University of Singapore, Singapore.

NG, P.K.L. (1991) A Guide to Freshwater Life in Singapore. Singapore Science Centre, Singapore.

NG, P.K.L. (1994) Freshwater habitats. In A First Look at Biodiversity in Singapore (eds Y.C. Wee \& P.K.L. Ng), pp. 23-34. National Council of the Environment, Singapore.

NG, P.K.L. (1995) Freshwater decapod crustaceans. In Rain Forest in the City: Bukit Timah Nature Reserve Singapore (eds S.C. Chin, R.T. Corlett, Y.C. Wee \& S. Geh), pp. 151-157. The Gardens' Bulletin, Singapore.

NG, P.K.L. (1997) The conservation status of freshwater prawns and crabs in Singapore with emphasis on the Nature Reserves. The Gardens' Bulletin, Singapore, 49, 267-272.

NG, P.K.L. \& LiM, K.K.P. (1992) The conservation of the Nee Soon freshwater swamp forest of Singapore. Aquatic Conservation: Marine and Freshwater Ecosystems, 2, 255-266.

NG, P.K.L., LiM, K.K.P. \& TAN, H.T.W. (2011) Uniquely Singapore: plants and animals known only from Singapore. In Singapore Biodiversity: An Encyclopedia of the Natural Environment and Sustainable Development (eds P.K.L. Ng, R.T. Corlett \& H.T.W. Tan), pp. 26-27. Editions Didier Millet, Singapore.

NG, P.K.L. \& TAN, C.G.S. (1995) Geosesarma notophorum sp. nov. (Decapoda, Brachyura, Grapsidae, Sesarminae), a terrestrial crab from Sumatra, with novel brooding behaviour. Crustaceana, 68, 390-395.

NG, P.K.L. \& YEO, D.C.J. (2007) Malaysian freshwater crabs: conservation prospects and challenges. In Proceedings of the 
Seminar on the Status of Biological Diversity in Malaysia and Threat Assessment of Plant Species in Malaysia, 28-30 June 2005 (ed. L. Chua), pp. 95-120. Forest Research Institute Malaysia, Kepong, Malaysia.

NParks (National Parks Board of Singapore) (2011) Construction Starts for Southeast Asia's First Ecological Corridor. Eco-Link@BKE to Link Two Nature Reserves Across the Expressway. Http://www.nparks.gov.sg/cms/index.php?option=com news\&task $=$ view $\& i d=264 \&$ Itemid $=50$ [accessed 13 January 2013].

Nyström, P., Stenroth, P., Holmqvist, N., Berglund, O., Larsson, P. \& Granelí, W. (2006) Crayfish in lakes and streams: individual and population responses to predation, productivity and substratum availability. Freshwater Biology, 51, 2096-2113.

ONG, K.M. (1965) A faunal study of a stream on Bukit Timah Hill. BSc. thesis. Department of Zoology, National University of Singapore, Singapore.

Rosemond, A.D., Reice, S.R., Elwood, J.W. \& Mulholland, P.J. (1992) The effects of stream acidity on benthic invertebrate communities in the south-eastern United States. Freshwater Biology, 27, 193-209.

Sutcliffe, D.W. \& Hildrew, A.G. (1989) Invertebrate communities in acid streams. In Acid Toxicity and Aquatic Animals (eds R. Morris, E.W. Taylor, D.J.A. Brown \& J.A. Brown), pp. 13-29. Cambridge University Press, Cambridge, UK.

Yeo, D.C.J. \& Lim, K.K.P. (2011) Freshwater ecosystems. In Singapore Biodiversity: An Encyclopedia of the Natural Environment and Sustainable Development (eds P.K.L. Ng, R.T. Corlett \& H.T.W. Tan), pp. 52-63. Editions Didier Millet, Singapore.

Yeo, D.C.J., NG, P.K.L., Cumberlidge, N., Magalhães, C., Daniels, S.R. \& CAMpos, M.R. (2008a) Global diversity of crabs
(Crustacea: Decapoda: Brachyura) in freshwater. Hydrobiologia, 595, 275-286.

Yeo, D.C.J., Shih, H.-T., Meier, R. \& NG, P.K.L. (2007)

Phylogeography of the freshwater crab genus Johora (Crustacea:

Brachyura: Potamidae) from the Malay Peninsula, and the origins of its insular fauna. Zoologica Scripta, 36, 255-269.

Yeo, D.C.J., TAN, S.H. \& NG, P.K.L. (2008b) Horseshoe crabs (Phylum Arthropoda: Subphylum Chelicerata: Class Merostomata) decapod crustaceans (Phylum Arthropoda: Subphylum Crustacea: Order Decapoda). In The Singapore Red Data Book: Threatened Plants and Animals of Singapore, 2nd edition. (eds G.W.H. Davidson, P.K.L. Ng \& H.C. Ho), pp. 110-128. Nature Society Singapore, Singapore.

Zhong, Z.C., Victor, T. \& Balasubramanian, R. (2001) Measurement of major organic acids in rainwater in Southeast Asia during burning and non-burning periods. Water, Air, and Soil Pollution, 130, 457-462.

\section{Biographical sketches}

DANIEL NG's research interests include freshwater stream ecology and conservation, herpetology, and climate change and other anthropogenic impacts. DARREN YEO studies freshwater ecology and biodiversity, aquatic invasions, and systematics and conservation of freshwater decapod crustaceans. Sivasothi N. is interested in the biodiversity, ecology and conservation of mangroves, decapod crustaceans and otters. Peter NG's research interests lie in the diversity and biology of marine and freshwater crabs in the Indo-West Pacific as well as crustacean and fish systematics. 